\title{
Effects of Alternative Policy Regimes on Foreign-Payments Imbalances
}

\author{
SÜBIDEY TOGAN*
}

Using a country-specific multisectoral general-equilibrium trade model the paper examines the consequences of outward- and inward-oriented development strategies. The analysis supports the view that the unwillingness of some of the developing countries' governments to pursue outward-oriented policies can be explained in terms of low trade-elasticity values supposedly perceived by the policy makers, and/or by the political power exercised by capitalists, who seem to lose most under outward-oriented policies.

\section{INTRODUCTION}

A recent article by Kemal Dervis, Jaime de Melo and Sherman Robinson [4] constitutes a significant advance for the analysis of foreign-exchange shortages in a developing economy. Moreover, their work has important implications for the evaluation of alternative adjustment mechanism for foreign-payments imbalances.

The crucial feature of the paper by Dervis et al. [4] is their combining of the existing descriptive analysis of the consequences of alternative adjustment mechanisms with a quantitative analysis that indicates relative importance of different policy regimes: inward orientation and outward orientation. They conclude that adjustment to an exogenous fall in foreign-exchange inflow by means of inwardoriented policies is three to four times as costly in terms of lost GDP as adjustment by means of outward-oriented strategies. The result is intuitively plausible to neo-classical economists confident of high values of foreign-trade elasticities. Surprisingly, however, the authors report an even more dramatic contrast when low values of foreign-trade elasticities are assumed. According to the authors, outward orientation is the best policy-regime in terms of minimizing GDP losses, and this result holds irrespective of the values of foreign-trade elasticities, depriving the structuralists of one of their main arguments.

*The author is Associate Professor in the Department of Econometrics, the Middle East Technical University, Ankara, Turkey. The work was done while the author was an Alexander von Humboldt Research Fellow at the Kiel Institute. The financial support from Alexander von Humboldt Foundation is gratefully acknowledged. The author is indebted to Egbert Gerken, Hasan Olgun and three anonymous referees of this journal for most useful comments. 
As is well known, the economic policies followed by many developing countries in the post-war period were greatly influenced by the ideas of structuralists such as Raul Prebish and Gunnar Myrdal. They maintained that developing countries should expand their manufacturing industries oriented towards domestic markets as adverse foreign market conditions for primary exports and lack of competitiveness in manufacturing exports would not permit the developing countries to attain high rates of economic growth by relying on export production. The developing countries, influenced by these ideas, adopted largely inward-oriented policies. In those countries the role of prices was de-emphasized. Output and input prices were distorted, and reliance was placed on non-price measures of import restrictions and credit allocations.

The slow-down of economic growth that eventually resulted from the pursuit of an inward-oriented development strategy led to policy reforms in several of these countries. The reforms, advocated by the neoclassicists, generally involved reducing import restrictions, applying a system of crawling pegs, providing subsidies to manufactured exports, adopting positive real-interest rates and introducing greater realism in the pricing of public utilities. Thus, the role of prices in resource allocation was emphasized. Under outward-oriented strategies, those countries aimed at producing products in which they have comparative advantage and at allowing imports to compete with all but a few of the domestically produced goods.

The 1970s provided further evidence of the relative merits of the outwardoriented and inward-oriented strategies. During this period, the oil-importing developing countries suffered various external shocks, which included the quadrupling of oil prices in 1973-74, the world recession of 1974-75 and the 160-percent increase in oil price in 1978. Given these shocks, the oil-importing developing countries had to make appropriate adjustment, and adjustment meant that countries had to achieve improvements in their balance of payments to regain their pre-shock growth path.

The effects of the external shocks of the 1970s under the two policy regimes have been analysed recently by various economists including Balassa [3] and the World Bank [14]. These studies concentrated largely on the analysis of actual adjustment policies, adopted by many of the non-OPEC developing countries to counter the adverse consequences of external shocks, and concluded that outwardoriented strategies had a superior performance in terms of exports, economic growth and employment.

The World Bank study [14] notes that a relatively large number of countries switched from inward-oriented to outward-oriented strategies, as the countries adopting the latter type of strategies weathered the effects of external shocks better than those with continued inward-orientation. But what is surprising is that a switch also occurred lately from outward-oriented policies back to inward-oriented policies.
In this paper, we examine empirically the effects of alternative policy regimes on foreign-payments imbalances, and ask the question why countries switch back from outward-oriented to inward-oriented development strategies. We are not concerned with short-run problems, but we concentrate on the study of the mediumterm to long-term problems. We use a computable general-equilibrium trade model, and incorporate into the model the structuralists' and neoclassicists' views by considering different values for trade elasticities. We create six plausible policy scenarios: inward-oriented and outward-oriented strategies under, respectively, low, medium and high trade-elasticity values. Low elasticities represent the views of the structuralists, whereas high elasticities represent the assumptions of high substitutability between domestic goods and imports, and high export demand elasticities employed by neoclassicists. In this way the dependence of the policies that minimize the GDP losses on the values of trade elasticities are highlighted. The paper also provides evidence of the effects of alternative policies on various income groups in the economy. The objective is to indicate the groups that have a vested interest in getting a specific policy implemented.

The analysis is based on a general-equilibrium trade model, developed for Turkey, a semi-industrial country. The model is described in Section 2. The different adjustment mechanisms considered, and the empirical results are presented in Section 3. Finally, conclusions follow in Section 4.

\section{THE MODEL}

The basic framework of our analysis is a multi-sectoral general-equilibrium trade model. The model, emphasising the importance of substitution effects in product and factor markets, determines both the commodity and factor prices and quantities endogenously. Following Armington [1;2], we make a distinction between domestically produced and imported commodities. For each sector, the domestically produced and imported commodities are considered not as perfect substitutes, as in classical models of trade theory, nor as perfect complements, as in two-gap models of trade and growth. Instead, the commodities are supposed to be imperfect substitutes, with the substitution possibilities represented by the values of trade substitution elasticity parameters.

The country is supposed to be small on the import side, so that the world prices of imported commodities are fixed. On the export side, it is assumed to face downward-sloping demand curves for each of the tradable domestic commodities. The responsiveness of export demands to changes in the world prices of exports are represented by the values of the export demand elasticity parameters. 
The equations of the model, drawn from Dixon et al. [6], are summarized in the Appendix. ${ }^{1}$ Equations A.1-A.9 describe the product and factor markets. Producers are assumed to minimize the cost of producing a given activity-level, subject to production functions of a three-level form. At the first level, we have the Leontief assumption of no substitution between commodity categories, or between them and an aggregate of primary factors. At the second level, we have CES aggregation functions describing substitution possibilities between domestic and imported commodities of the same type, and also CRESH functions describing substitution between aggregate primary factors - labour, capital and land. ${ }^{2}$ At the third level we have CRESH functions describing substitution prospects between different types of land within the aggregate land category. The solution to the optimization problems yields the system of commodity demand equations for current production and capital creation, summarized by equations A.1 and A.2, and also the system of factor demand equations, summarized by equations A.3-A.6 and A.9.

Formally, the production function in sector $j$ is written as follows:

$$
Q_{j}=\min \left\{\frac{X_{i j}}{a_{i j}}, \ldots, \frac{X_{n j}}{a_{n j}}, \frac{Y_{j}}{b_{j}}\right\}
$$

where $Q_{j}$ denotes the output of sector $j, X_{i j}$ the effective intermediate input of sector $i$ into sector $j, a_{i j}$ the fixed input-output coefficient, $Y_{j}$ effective primary input into sector $j$, and $b_{j}$ the required amount of $Y_{j}$ to produce one unit of $Q_{j}$ To produce $Q_{j}$ units of output, the producer requires $X_{i j}=a_{i j} Q_{j}$ units of effective intermediate input and $Y_{j}=b_{j} Q_{j}$ units of effective primary input. Given $X_{i j}$ the producer decides on the amounts of intermediate inputs from domestic and im. ported sources that will be employed. Thus, by distinguishing these two sources we allow for the possibility that imported commodities may not be perfectly substitutable for the corresponding domestic product, and this idea of imperfect substitutability is captured by assuming that domestic and imported commodities provide the effective input according to the CES equation

$$
X_{i j}=\gamma_{i j}^{1}\left[\alpha_{i j}^{1} D_{i j}^{-} \rho_{i j}^{1}+\left(1-\alpha_{i j}^{1}\right) M_{i j}^{-} \rho_{i j}^{1}\right]^{-1 / \rho_{i j}^{1}}
$$

where $D_{i j}$ denotes the domestic intermediate input of commodity $i$ by sector $j, M_{i j}$ the imported intermediate input of commodity $i$ by sector $j, \alpha_{i j}^{1}$ the input weight,

${ }^{1}$ Dixon et al. provide an exhaustive algebraic treatment of the derivation of the equation system. A complete list of the model equation is contained in Vincent [13]. Togan [12] gives a full description of our model.

${ }^{2}$ For a discussion of CRESH functions, see Hanoch [9] $\rho_{i j}^{1}$ a measure of the ease of substitution, and $\gamma_{i j}^{1}$ the normalizing constant. On the other hand, given $Y_{j}$, the producer decides on the amounts of labour, capital and land to be employed. In particular, we assume that labour $\left(L_{j}\right)$, capital $\left(K_{j}\right)$ and land $\left(A_{j}\right)$ in the agricultural sector are combined to form effective units of the primaryfactor input according to the CRESH function:

$$
\left(\frac{L_{j}}{Y_{j}}\right)^{\delta_{\ell}}\left(\frac{\pi_{\ell}}{\delta_{\ell}}\right)+\left(\frac{K_{j}}{Y_{j}}\right)^{\delta_{k}}\left(\frac{\pi_{k}}{\delta_{k}}\right)+\left(\frac{A_{j}}{Y_{j}}\right)^{\delta_{a}}\left(\frac{\pi_{a}}{\delta_{a}}\right)=\nu
$$

where $\delta_{i}, \pi_{i}(i=\ell, k, a)$ and $v$ denote the constant parameters. The advantage of this function over CES is that it allows the elasticity of substitution between labour and capital to differ from that between capital and agricultural land. Regarding agricultural land we assume that it is an aggregate of irrigated and rain-fed land, and that the aggregation function is of the form:

$$
A_{j}=\gamma_{j}^{01}\left[\alpha_{j}^{01} A_{I j}^{-\rho_{j}^{01}}+\left(1-\alpha_{j}^{01}\right) A_{R j}^{-\rho_{j}^{01}}\right]^{-1 / \rho_{j}^{01}}
$$

where $A_{I j}$ denotes irrigated land, $A_{R j}$ the rain-fed land, and $\left(\gamma_{j}^{01}, \alpha_{j}^{01}, \rho_{j}^{01}\right)$ the constant parameters. In the non-agricultural sectors we abstract from consideration of land as an input and assume that labour and capital provide the effective primary input according to the CES-equations:

$$
Y_{j}=\gamma_{j}^{0}\left[\alpha_{j}^{0} L_{j}^{-} \rho_{j}^{0}+\left(1-\alpha_{j}^{0}\right) K_{j}^{-} \rho_{j}^{0}\right]^{-1 / \rho_{j}^{0}}
$$

We assume that producers are competitive. They consider all input and output prices as exogenously given, and select the input levels which minimize the cost of producing each level of output. The solution of this minimization problem yields the input demand functions summarized by equations A.1 - A.9 in the Appendix.

On the final demand side, we consider consumption and investment demand. The average consumer is assumed to maximize the utility function of the StoneGeary form, ${ }^{3}$ yielding the well-known linear expenditure system. Given the utility function of the form

$$
u\left(C_{1}, \ldots, C_{n}\right)=\sum_{i=1}^{n} \bar{\delta}_{i} \ln \left(C_{i}-\Theta_{i}\right)
$$

where $C_{i}$ denotes effective consumption of good $i$, and $\bar{\delta}_{i}$ and $\Theta_{i}(i=1, \ldots, n)$ are the constant parameters with $\bar{\delta}_{i}>0$ for all $i$ and $\sum_{i=1}^{n} \bar{\delta}_{i}=1$. We allow the consumer to satisfy his demand for any good $i$ by drawing on imported and domestic sources,

${ }^{3}$ See Stone [11] and Geary [8] 
with the two sources providing imperfect substitutes. The idea of imperfect substitutability is captured again by writing the effective consumption of good $i$ according to the CES function

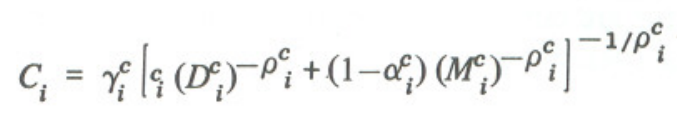

where $D_{i}^{c}$ denotes consumption of domestic commodity $i$ and $M_{i}^{c}$ represents consumption of imported commodity. Maximization of the nested utility function, subject to the budget constraint, yields the consumption functions of equations A.1-A.2 in the Appendix. Finally, regarding the production of capital goods we write the production functions as

$$
Z_{j}=\min \left\{\frac{X_{j}^{I}}{a_{\ell j}^{I}}, \ldots, \frac{X_{n j}^{I}}{a_{n j}^{I}}\right\}
$$

where $Z_{j}$ denotes the number of units of fixed capital created for industry $j, X_{i j}^{I}$ the effective input of good $i$ for creating capital for industry $j$, and $a_{i j}^{I}$ the fixed positive production coefficient. The effective input is provided by domestic and imported sources according to the CES function:

$$
X_{i j}^{I}=\gamma_{i j}^{I}\left[\alpha_{i j}^{I}\left(D_{i j}^{I}\right)^{-\rho_{i j}^{I}}+\left(1-\alpha_{i j}^{I}\right)\left(M_{i j}^{I}\right)^{-\rho_{i j}^{I}}\right]^{-1 / \rho^{I}}{ }_{i j}
$$

where $D_{i j}^{I}$ denotes the demand for capital creation of domestic commodity $i$ by sector $j$ and $M_{i j}^{I}$ the demand for capital creation of imported commodity $i$ by sector $j$. We assume that producers of capital treat input prices as beyond their control, and for any amount of capital creation $\left(Z_{j}\right)$ they choose the domestic and imported inputs to minimize the cost of production. The solution of this minimization problem yields the demand functions for capital creation given in equations A.1-A.2 in the Appendix.

Competitive pricing behaviour is imposed by equations A.10 - A.14, relating prices to cost for each of the activities of current production, capital creation, exporting and importing. Equations A.15 and A.16 define, respectively, the consumer price index and the capital goods price index. We also note that the system of equations summarized in the Appendix is homogenous of degree zero in commodity and factor prices so that only relative prices can be determined. Some sort of normalization of prices is required. In the following we assume that the index of consumer prices is constant, implying that monetary authorities control the money supply during the adjustment period.
Although time enters the model through equations A.21 - A.25, which determine the accumulation of capital, the model is essentially static. Equation A.21 defines the current rate of return on capital in industry $j$. We assume that investors are cautious in assessing the effects of expanding capital stock, and define the expected rate of return as follows:

$$
R_{j}(1)=R_{j}(0)\left[\frac{K_{j}(1)}{K_{j}(0)}\right]^{-\bar{\beta}_{j}}
$$

where $K_{j}(0)$ denotes the current level of capital stock, $K_{j}(1)$ the level of capital stock at the end of the period (final period), and $\bar{\beta}_{j}$ the elasticity of the expected rate of return schedule in industry $j$ with respect to the increase in the planned capital stock in industry $j$. We assume that total investment is so allocated that the expected rate of returns are equal across all industries so that equation A.22 is satisfied. Furthermore, we assume that total capital stock is fixed, and that capital is allocated in such a way that the return on capital in each sector equals the common absolute rate of return on capital.

Consideration of the equations in Section 5 of the Appendix reveals that the model has been closed with $L^{A} / L^{N A}$ and $i / c$ ratios considered as having been determined exogenously. Obviously, one could consider the $i / c$ ratio as depending on, among others, monetary and fiscal policies, and the $L^{A} / L^{N A}$ ratio as depending on the ratio of the rural wage rate to the urban wage rate. ${ }^{4}$ But this will complicate the analysis considerably, and it is unnecessary as the effect of external shocks on these variables can be neglected within the framework considered in this paper.

\section{EFFECTS OF ALTERNATIVE POLICY REGIMES}

The model described above and presented in the Appendix is used in this section to study the effects of outward-oriented and inward-oriented policies. Since this type of analysis requires determination of parameter values and initialization of the model, we consider the case of Turkey, the structural characteristics of which are summarized in Table 1. Following Dervis et al. [4], we assume a sudden and permanent decrease in the normal flow of foreign resources $(\bar{F}$ in equation A.20 in the Appendix). The shortfall in foreign-resource transfer is assumed to amount to $\$ 650$ million, constituting about 3 percent of the Turkish GNP in the base year. Faced with this shock, the country has to adjust itself to it. It can respond to the external shock by squeezing imports, which would slow down the growth. Alternatively, it could try to finance the current-account deficit by running down foreignexchange reserves or borrowing on international markets. In this paper we do not 
consider such a line of action, but assume instead that the country is able to reduce its current-account deficit to sustainable levels over a period of about five years.

Faced with such a task the country can adopt a variety of policy measures to overcome the effects of the external shock. In this paper we broadly consider two sets of policies: "outward-oriented policies" and "inward-oriented policies". By inward-oriented policies we imply a mechanism that de-emphasizes the role of prices and places reliance on non-price measures in resource allocation. In particular, we assume that the exchange rate has been fixed by the government below its equilibrium level. On the other hand, outward-oriented policies represent a mechanism whereby all prices, including the exchange rate, are flexible. Prices so adjust them selves as to equate demand and supply in commodity and factor markets as well as in the balance of payments. Thus, under outward-oriented strategies the country aims at producing products in which it has a comparative advantage.

Within the general-equilibrium trade model of Section 2, we represent outwardoriented policies by the system summarized in the Appendix. In this sytem, the decrease in foreign capital inflow $(\bar{F})$ generates an excess demand for foreign exchange, exerting an upward pressure on the exchange rate $(E)$. The increase in the exchange rate increases the price of the tradables. Since the price level is assumed to be constant, the price of the non-tradables has to decrease. As a result, resources will be attracted away from the non-tradables towards the tradable sector.

Under inward-oriented policies, the exchange rate is fixed. Given the excess demand situation for foreign exchange, caused by the shortfall in the inflow of foreign resources, we assume that foreign exchange is allocated through rationing. In particular, we suppose, following the approach of Dervis et al. [4], that a free market develops for the scarce imports. In this case, those who demand the imported commodities will bid the price of imports over the customs-clearing price, so that positive premium rates emerge. Equation A. 14 of the model, i.e.

$$
p_{2 j}=\bar{p}_{2 j}\left(1+\bar{t}_{j}\right) E
$$

can no longer hold. Since under competition the premium rate has to be uniform across all sectors, the above equations will be replaced by the relation

$$
p_{2 j}=\bar{p}_{2 j}\left(1+\bar{t}_{j}+P R\right) \bar{E}
$$

where $P R$ denotes the premium rate, the new endogenous variable. Given the exogenously specified value of the exchange rate $(\bar{E})$, the domestic price of imports will increase with increases in the premium rate. Thus, under inward-oriented policies we assume that adjustment will be achieved through changes in the domestic price of imports, until import premia so adjust themselves as to clear the balance of payments. 
The increase in import premia increases the domestic price of imports, which in turn has three different effects. First, the intermediate input costs increase considerably more in those sectors which have a high ratio of imported inputs to total intermediate inputs. Since the increase in intermediate input costs reduces the value added by the sector, sectors with the relatively largest value-added decreases will be adversely affected. These will be the sectors which have a high ratio of imported inputs to total intermediate inputs. The increase in the domestic price of imports also has a second effect, which refers to the effect on domestic prices of home-produced goods due to changes in domestic demand. As long as domestic and imported commodities are close substitutes (complements), domestic demand for home-produced goods will increase (decrease) with the increase in the domestic price of imports. The increase (decrease) in domestic demand in turn increases (decreases) the price of the commodity, causing an increase (decrease) in the value added. Thus, the increase in the premium rate will raise (reduce) the value added in import-substituting (complementing) sectors. As a result, import-substituting sectors will draw resources away from the rest of the economy. Finally, one should note that in the case of an import-substituting sector, the increase in the domestic price of imports will lead to a decrease in the final demand for the commodity. Ignoring this last effect, one could state that the increase in premium rate will attract resources away from the nontradable, exportable and import-complementing sectors towards importsubstituting sectors, which do not have a relatively high ratio of imported inputs to total intermediate inputs.

To re-examine the debate between the structuralists and the neo-classicists, we use different assumptions about the values of key trade elasticities. In particular, we consider three sets of values for these parameters. We call "low elasticities" the set of values for trade-substitution and export-demand elasticities, which represents the views of the structuralists. "Medium elasticities" refer to the set of trade elasticities which are three times those under "low elasticities", and "high elasticities" refer to the set of trade elasticities which are three times those under "medium elasticities". Thus high elasticities represent the assumption of high substitutability between domestic goods and imports and of high export-demand elasticities as assumed by the neoclassicists. ${ }^{5}$

To study the effects of the exogenous shock under different policy regimes, we assume that the economy is initially in internal and external equilibrium, so that the equations in the Appendix are satisfied. Next, we consider the exogenous shock. To analyse the effects of this shock under the policy of outward orientation, we linearize the system by logarithmic differentiation, and then solve the endogenous variables by using simple matrix methods. Under the policy of inward orientation, we use

\footnotetext{
${ }^{5}$ See the last two columns of Table 1 for the values of trade elasticities used in the model.
}

the same set of equations, but replace now equation A.14 in the Appendix by the relation (1) given above. The results of these experiments are summarized in Tables $2-5$.

From Table 2 it follows that restoration of equilibrium in the balance of payments requires a 2.3 -percent devaluation under high elasticities, and a 40.4-percent devaluation under low elasticities. Thus, the required rate of devaluation increases with decreases in the values of trade elasticities. On the other hand, the exchange rate under rationing is fixed. But now premium rate increases due to rationing, causing an increase in the domestic price of imports, which in turn exceeds the increase under devaluation. Furthermore, we note that the premium rate increases with decreases in the values of trade elasticities.

From Table 3, which summarizes the values of aggregate export- and importelasticities, it follows that these elasticities depend on policy regimes, and that, therefore, they have to be used with care.

Finally, we note that the real GDP declines in all cases, and that for a given policy regime, the GDP loss increases with decreases in trade elasticities. Comparisons of the GDP losses under the two policy regimes reveal that outward-oriented strategies are not always the best policy regime in terms of minimizing GDP changes. Contrary to the conclusions of Dervis et al. [4], the adoption of outward-oriented policies under elasticity pessimism leads to larger decreases.

Now, using the model, we can re-examine the debate between the structuralists and the neoclassicists. From Table 2 it follows that the real GDP loss increases with decreases in trade-elasticity values irrespective of whether the country follows outward-oriented or inward-oriented trade strategies. Comparisons of the GDP losses under the two policy regimes reveal that outward-oriented strategies are not always the best policy regime in terms of minimizing GDP changes. Contrary to the conclusions of Dervis et al. [4] who maintain that adjustment to an exogenous fall in foreign-exchange inflow by means of inward-oriented policies is three to four times as costly in terms of the lost GDP as adjustment by means of outward-oriented strategies, adoption of outward-oriented policies under elasticity pessimism leads to larger decreases in the GDP than adoption of inward-oriented policies. ${ }^{6}$ From Table 2 it follows that outward-oriented policies are more costly in terms of GDP under low elasticities, and that inward-oriented policies are more costly under medium and high elasticities. Thus, in terms of minimizing GDP losses the best choice of a policy regime depends on the values of trade elasticities. Under the conditions assumed by structuralists, the best choice turns out to be one of inward-oriented strategies and, under the conditions assumed by neoclassicals, that of outward-oriented strategies.

${ }^{6}$ For a similar result, see Dervis et al. [5]. 
Table 2

Macroeconomic Effects of Alternative Policy Regimes (Percent Changes from the Base Run)

\begin{tabular}{|c|c|c|c|c|c|c|}
\hline & \multicolumn{3}{|c|}{ Outward-Oriented Strategies } & \multicolumn{3}{|c|}{ Inward-Oriented Strategies } \\
\hline & $\begin{array}{c}\text { High } \\
\text { Elasticities }\end{array}$ & $\begin{array}{c}\text { Medium } \\
\text { Elasticities }\end{array}$ & $\begin{array}{c}\text { Low } \\
\text { Elasticities }\end{array}$ & $\begin{array}{c}\text { High } \\
\text { Elasticities }\end{array}$ & $\begin{array}{c}\text { Medium } \\
\text { Elasticities }\end{array}$ & $\begin{array}{c}\text { Low } \\
\text { Elasticities }\end{array}$ \\
\hline Real GDP & -0.37 & -0.91 & -4.09 & -0.94 & -1.19 & -1.84 \\
\hline Exchange Rate & 2.32 & 7.83 & 40.45 & - & - & - \\
\hline $\begin{array}{l}\text { Domestic Price } \\
\text { of Imports }\end{array}$ & 2.32 & 7.83 & 40.45 & 11.85 & 36.30 & 106.70 \\
\hline $\begin{array}{l}\text { Foreign Price } \\
\text { of Exports }\end{array}$ & -2.44 & -8.29 & -42.30 & -0.60 & -1.51 & -3.70 \\
\hline Real Imports (volume) & -5.60 & -6.58 & -12.43 & -23.35 & -24.78 & -27.04 \\
\hline Real Exports (volume) & 31.74 & 36.24 & 62.20 & 5.48 & 4.43 & 3.53 \\
\hline Real Wage & -1.05 & -2.39 & -9.16 & -2.44 & -6.81 & -18.91 \\
\hline Share of Labour in GDP & -0.68 & -1.48 & -5.07 & -1.50 & -5.62 & $-17,07$ \\
\hline
\end{tabular}

${ }^{1}$ Weighted average using import share weights.

${ }^{2}$ Weighted average using export share weights.

Table 3

Aggregate Export and Import Elasticities

\begin{tabular}{|c|c|c|c|c|c|c|}
\hline & \multicolumn{3}{|c|}{ Outward-Oriented Strategies } & \multicolumn{3}{|c|}{ Inward-Oriented Strategies } \\
\hline & $\begin{array}{c}\text { High } \\
\text { Elasticities }\end{array}$ & $\begin{array}{c}\text { Medium } \\
\text { Elasticities }\end{array}$ & $\begin{array}{c}\text { Low } \\
\text { Elasticities }\end{array}$ & $\begin{array}{c}\text { High } \\
\text { Elasticities }\end{array}$ & $\begin{array}{c}\text { Medium } \\
\text { Elasticities }\end{array}$ & $\begin{array}{c}\text { Low } \\
\text { Elasticities }\end{array}$ \\
\hline Export Elasticity & 13.01 & 4.37 & 1.47 & 9.13 & 2.93 & 0.95 \\
\hline Import Elasticity & 2.41 & 0.84 & 0.31 & 1.97 & 0.68 & 0.25 \\
\hline
\end{tabular}

Table 4

Terms of Trade Effect (\% Changes from Base Run)

\begin{tabular}{|c|c|c|c|c|c|c|}
\hline & \multicolumn{3}{|c|}{ Outward-Oriented Strategies } & \multicolumn{3}{|c|}{ Inward-Oriented Strategies } \\
\hline & $\begin{array}{c}\text { High } \\
\text { Elasticities }\end{array}$ & $\begin{array}{l}\text { Medium } \\
\text { Elasticities }\end{array}$ & $\begin{array}{c}\text { Low } \\
\text { Elasticities }\end{array}$ & $\begin{array}{c}\text { High } \\
\text { Elasticities }\end{array}$ & $\begin{array}{l}\text { Medium } \\
\text { Elasticities }\end{array}$ & $\begin{array}{c}\text { Low } \\
\text { Elasticities }\end{array}$ \\
\hline Terms of Trade Effect & -0.21 & -0.70 & -3.56 & -0.05 & -0.13 & -0.31 \\
\hline $\begin{array}{l}\text { Real GDP at constant } \\
\text { base-year prices }\end{array}$ & -0.16 & -0.21 & -0.53 & -0.89 & -1.06 & -1.53 \\
\hline
\end{tabular}


The ranking of the two policy regimes changes completely as we abstract from

The ranking of the real consideration of changes in the terms of trade effects and which we GDP that abstracts from consideration of the terms of trade effects and and the call GDP at constant base-year prices, declines as before in all cases, and trategies decline is smaller when elasticities are high. Furthermore, outward-oriented strategies are now the best regime, irrespective of the values of trade elasticities. Thus, by bstracting from changes in the terms of trade we get the same ordering of policy regimes as derived by Dervis et al. [4]. But this approach has its shortcomings. The dijustment to external shocks takes about four to five years, and over this period the terms of trade change, the extent of which is summarized in Table 4 . To be a satisfactory measure of changes in potential welfare, the GDP, over a period of about five years, has to incorporate the changes in the terms of trade.

From the above considerations it follows that the reason why our result deviate from those of Dervis et al. [4] is that our measure of GDP incorporates the terms of trade changes, whereas the measure of GDP used by Dervis et al. completely abstracts from these changes.

Comparing the figures for real GDP in Table 2 yields a ranking of alternative policies different from that of Dervis et al. [4]. Under low elasticities, inwardoriented strategies are the best policy, and under medium and high elasticities out ward-oriented strategies are the best policy. Thus, one of the reasons why policy makers in a large number of developing countries have adopted interventionist policies could now be explained by the policy makers' perception of the trade elasticity values. Thus, policy makers adopting outward-oriented strategies could be supposed to concentrate on either real GDP measures abstracting from terms of trade changes or on real GDP measures incorporating terms of trade effects. However, in the case of Turkey whose aggregate export elasticity is 3.1 , outward-oriented strategies would be the best policy. ${ }^{7}$

An alternative explanation of why policy makers have adopted interventionist policies is provided by de Melo and Robinson [10], whose arguments could be explained with the help of Table 3. From this table it follows that after the externa shock workers lose and capitalists gain regardless of the adjustment mechanism. But the loss of workers under inward-oriented strategies is about twice as large as that under outward-oriented strategies, and capitalists gain much more under inward oriented strategies than under outward-oriented strategies. The reason why certain policies are adopted could further be explained in terms of the political power of the two socio-economic groups. Considering workers and capitalists as homogenous

${ }^{7}$ When trade elasticities are 70 percent of those under medium elasticities, the GDP loss under outward-oriented strategies equals that under inward-oriented strategies. In this case the aggregate export elasticity equals 3.1 under outward-oriented strategies and 2.03 under inwardoriented strategies. 
groups, one could state that as the relative political power of capitalists increases, the country switches from outward-oriented strategies to inward-oriented policies, and as the relative political power of workers increases the country adopts the non-interventionist policy of outward-oriented strategies. Since workers form a large fraction of the population, one would expect the policy of outward-oriented strategies to be adopted in countries where franchise matters and where majority rule determines the policy regime, provided the electorate is well-informed about the benefits and costs of alternative policy regimes.

\section{CONCLUSIONS}

This paper has re-examined the consequences of the two policy regimes: outward-oriented and inward-oriented policies. Using a general-equilibrium trade model, we have shown that outward-oriented strategies are more costly in terms of the lost GDP under conditions assumed by structuralists, and that inward-oriented strategies are more costly in terms of the lost GDP under conditions assumed by neoclassicals, when the measure of GDP incorporates changes in the terms of trade. Thus, our analysis supports the view that in terms of minimizing GDP losses the best choice of a policy regime depends on the values of trade elasticities. Furthermore, the choice of policy regimes has a significant impact on the distribution of income. Thus, the unwillingness of some of the developing countries' governments to pursue outwardoriented policies could be explained in terms of the low trade-elasticity values supposedly perceived by the policy makers of those countries, and/or by the political power exercised by capitalists, who seem to lose most under outward-oriented policies. 


\section{Appendix}

\section{EQUATIONS OF THE MODEL}

(Exogenous variables and parameters are denoted by letters with a bar)

\section{Product and factor markets}

$$
\begin{aligned}
& \sum_{j=1}^{n} D_{i j}\left(P_{1 i}, P_{2 i}, Q_{j}\right)+D_{i}^{c}\left(P_{11}, \ldots, P_{1 n}, P_{21}, \ldots, P_{2 n}, C\right)+ \\
& \sum_{j=1}^{n} D_{i j}^{I}\left(P_{1 i}, P_{2 i}, Z_{j}\right)+E_{i}=Q_{i} \quad(i=1, \ldots, n) \\
& \sum_{j=1}^{n} M_{i j}\left(P_{1 i}, P_{2 i}, Q_{j}\right)+M_{i}^{c}\left(P_{11}, \ldots, P_{1 n}, P_{21}, \ldots, P_{2 n}, C\right)+ \\
& \sum_{j=1}^{n} M_{i j}^{I}\left(P_{1 i}, P_{2 i}, Z_{j}\right)=M_{i} \\
& \sum_{j=1}^{n} L_{j}^{A}\left(w_{A}^{1}, w_{j}^{2}, w_{1}^{3}, w_{2}^{3}, Q_{j}\right)=L^{A} \quad(i=1, \ldots, n) \\
& j=\sum_{A}^{n+1} L_{j}^{N A}\left(w_{N A}^{1}, w_{j}^{2}, Q_{j}\right)=L^{N A} \\
& K_{j}^{A}\left(w_{A}^{1}, w_{j}^{2}, w_{1}^{3}, w_{2}^{3}, Q_{j}\right)=K_{j}^{A}(0) \quad\left(j=1, \ldots, n_{A}\right) \\
& K_{j}^{N A}\left(w_{N A}^{1}, w_{j}^{2}, Q_{j}\right)=K_{j}^{N A}(0) \quad\left(j=n_{A}+1, \ldots, n\right) \\
& L^{A}+L^{N A}=\bar{L}_{j} \quad(\ell=1,2) \\
& \sum_{j=1}^{n} K_{j}^{A}(0)+\sum_{j=n}^{n} K_{A}^{+1} K_{j}^{N A}(0)=\bar{K}(0) \quad \\
& \sum_{j=1}^{n} A_{j}^{\ell}\left(w_{A}^{1}, w_{j}^{2}, w_{1}^{3}, w_{2}^{3}, Q_{j}\right)=A^{-\ell}
\end{aligned}
$$

where

$$
\begin{aligned}
D_{i j}\left(M_{i j}\right)= & \text { inter-industry demand of domestic (imported) } \\
& \text { commodity } i \text { by sector } j
\end{aligned}
$$

$D_{i}^{c}\left(M_{i}^{c}\right)=$ consumption demand of domestic (imported) commodity $i$ 
$D_{i j}^{I}\left(M_{i j}^{I}\right)=$ demand for capital creation of domestic (imported) commodity $i$ by sector $j$

$P_{1 i}\left(P_{2 i}\right)=$ price of domestic (imported) commodity $i$

$Q_{i}\left(M_{i}\right)=$ output (import) of commodity $i$

$E_{i} \quad=$ export of domestic commodity $i$

C = total consumption expenditure

$Z_{j} \quad=$ investment by sector of destination

$L_{j}^{A} \quad=$ demand for agricultural labour by sector $j$

$L_{j}^{N A} \quad=$ demand for non-agricultural labour by sector $j$

$L^{A} \quad=$ agricultural labour

$L^{N A} \quad=$ non-agricultural labour

$\bar{L} \quad=$ total labour force

$K_{j}^{A}(0)=$ demand for capital by agricultural sector $j$

$K_{j}^{N A}(0)=$ demand for capital by non-agricultural sector $j$

$A_{j}^{\ell} \quad=$ demand for land category $\ell$ by sector $j$

$\bar{A}^{\ell} \quad=$ supply of land category $\ell$

$w_{A}^{1} \quad=$ average wage of agricultural labour

$w_{N A}^{1} \quad=$ average wage of non-agricultural labour

$w_{j}^{2} \quad=$ rental rate of capital by sector $j$

$w_{\ell}^{3} \quad=$ average rent of land category $\ell$

$\bar{K}(0) \quad=$ aggregate capital
2. Prices

$$
\begin{aligned}
P_{1 j} Q_{j}= & \sum_{i=1}^{n} P_{1 i} D_{i j}+\sum_{i=1}^{n} P_{2 i} M_{i j}+w_{A}^{1} L_{j}^{A}+w_{j}^{2} K_{j}^{A}(0) \\
& +\sum_{\ell=1}^{2} w_{\ell}^{3} A_{j}^{\ell}+\overline{t d}_{j} P_{1 j} Q_{j} \quad\left(j=1, \ldots, n_{A}\right) \\
P_{1 j} Q_{j}= & \sum_{i=1}^{n} P_{1 i} D_{i j}+\sum_{i=1}^{n} P_{2 i} M_{i j}+w_{N A}^{1} L_{j}^{N A}+w_{j}^{2} K_{j}^{N A} \\
& +t \bar{d}_{j} P_{1 j} Q_{j} \quad\left(j=n_{A}+1, \ldots, n\right) \\
\pi_{j} Y_{j}= & \sum_{i=1}^{n} P_{1 i} D_{i j}^{I}+\sum_{i=1}^{n} P_{2 i} M_{i j}^{I} \\
P_{1 j}= & P_{1 j}^{*}\left(1+\bar{v}_{j}\right) E \\
P_{2 j}= & \bar{P}_{2 j}\left(1+\bar{t}_{j}\right) E \\
\bar{\Omega}^{c}= & \Omega^{c}\left(P_{11}, \ldots, P_{1 n}, P_{21}, \ldots, P_{2 n}\right) \\
\Omega^{I}= & \Omega^{I}\left(\pi_{1}, \ldots, \pi_{n}\right)
\end{aligned}
$$

where

$$
\overline{t d}{ }_{j}=\text { indirect tax rate of sector } j
$$

$\pi_{j}=$ price of capital in sector $j$

$P_{1 j}^{*}=$ foreign price of exports of sector $j$

$\bar{P}_{2 j}=$ foreign price of imported commodity $j$

$\bar{v}_{j}=$ export subsidy rate of sector $j$

$E$ = exchange rate

$\bar{t}_{j}=$ tariff rate of sector $j$

$\bar{\Omega}^{c}=$ consumer price index

$\Omega^{I}=$ capital goods price index 
3. Foreign trade

$E_{i}=\bar{E}_{i} P_{1 i}^{\star} \bar{\eta}_{i}$

$e=\sum_{j=1}^{n} P_{1 j}^{*} E_{j}$

$m=\sum_{j=1}^{n} \bar{P}_{2 j} M_{j}$

$m \cdot e=\bar{F}$

where

$\eta_{i}=$ export demand elasticity in sector $i$

$e=$ foreign currency value of exports

$m=$ foreign currency value of imports

$\bar{F}=$ net inflow of foreign exchange

4. Capital Accumulation

$R_{j}(0)=\frac{w_{j}^{2}}{\pi_{j}}-\bar{d}_{j}$

$R_{j}(0)\left[\frac{K_{j}(1)}{K_{j}(0)}\right]^{-\bar{\beta}_{j}}$

$j=1, \ldots, n$

$R_{j}(0)=R \quad \bar{R}_{j}$

$j=1, \ldots, n$

$K_{j}(1)=K_{j}(0)+Y_{j}-\bar{d}_{j} K_{j}(0) \quad j=1, \ldots, n$

$I=\sum_{j=1}^{n} \pi_{j} Y_{j}$

where

$R_{j}(0)=$ rate of return on capital in sector $j$

$\bar{\beta}_{j}=$ elasticity of the expected rate of return schedule in industry $j$ with respect to increases in the planned capital stock in industry $j$

$R=$ absolute rate of return on capital
$\bar{R}_{j}=$ variable representing the ratio of rate of return on capital in sector $j$ to absolute rate of return on capital

$\bar{d}_{j}=$ rate of depreciation of capital in sector $j$

$A \quad=$ expected rate of return on capital

$K_{j}(1)=$ capital stock of sector $j$ in the final period

$I \quad=$ nominal investment

\section{Miscellaneous}

$$
\begin{aligned}
c & =C / \Omega^{-c} \\
i & =I / \Omega^{I} \\
\frac{L^{A}}{L^{N A}} & =\bar{f}_{L}
\end{aligned}
$$$$
w_{k}^{R^{1}}=w_{k}^{1} / \bar{\Omega}^{c}
$$

$i / c=\bar{f}$

$G D P=$

where

$c=$ real consumption

$i=$ real investment

$\bar{f}_{L} \quad=$ variable representing the ratio of agricultural labour to non-agricultural labour

$=$ real investment

$w_{k}^{R^{1}}=$ real wage of labour category $k(k=A N A)$

$\bar{f} \quad=$ variable representing the ratio of real investment to real consumption

$G D P=$ real gross domestic product 


\section{REFERENCES}

1. Armington, P.S. "Adjustment of Trade Balances: Some Experiments with a Model of Trade among Many Countries". IMF Staff Papers. Vol. 17, No. 3. November 1970.

2. Armington, P.S. "The Geographic Pattern of Trade and the Effects of Price Changes”. IMF Staff Papers. Vol. 16, No. 2. July 1969.

3. Balassa, B. "The Newly Industrializing Developing Countries after the Oil Crisis". Weltwirtschaftliches Archiv. Vol. 17. 1981.

4. Dervis, K., J, de Melo and S. Robinson. "A General Equilibrium Analysis of Foreign Exchange Shortages in a Developing Economy". Economic Journal. Vol. 91, No. 364. December 1981.

5. Dervis, K., J. de Melo and S. Robinson. General Equilibrium Models for Development Policy. Cambridge: Cambridge University Press. 1982.

6. Dixon, P.B., B.R. Parmenter and D.P. Vincent. ORANI A Multisectoral Model of the Australian Economy. Amsterdam: North-Holland. 1982.

7. Fischer, G., and K. Frohberg. Simplified National Models: The Condensed Version of the Food and Agricultural Model System of the International Institute for Systems Analysis. Laxenburg, Austria: IIASA. 1980. (WP-80-56)

8. Geary, R.C. "A Note on 'A Constant Utility Index of the Cost of Living'." Review of Economic Studies. Vol. 18. 1950-51.

9. Hanoch, G. "CRESH Production Functions". Econometrica. Vol. 39, No. 5. September 1971.

10. de Melo, J., and S. Robinson. "Trade Adjustment Policies and Income Distribution in Three Archetype Developing Economies'. Journal of Development Economics. Vol. 10, No. 1. February 1982.

11. Stone, R. "Linear Expenditure Systems and Demand Analysis: An Application to the Pattern of British Demand". Economic Journal. Vol. 64. September 1954.

12. Togan, S. "A General Equilibrium Model of the Turkish Economy: Sectoral Design, Data Base and Parameter Estimates". Ankara: Dept. of Economics, Middle East Technical University. 1982. (Unpublished paper)

13. Vincent, D.P. Multisectoral Economic Models for Developing Countries: A Theoretical Framework and an Illustration of their Usefulness for Determining Some Implications of UNCTAD Proposals for Commodity Market Reforms. Kiel: Institut Für Weltwirtschaft. 1981. (Kiel Working Paper,No. 117)

14. World Bank. World Development Report, New York: Oxford University Press. 1981. 